\title{
EVALUATION OF THE ANTIFUNGAL ACTIVITIES OF THREE ESSENTIAL OIL COMPONENTS AGAINST PENICILLIUM EXPANSUM SPORES
}

\author{
BARKAI HASSAN, ELABED SOUMYA, GUISSI SANAE, IBNSOUDA KORAICHI SAAD*
}

\author{
Laboratory of Microbial Biotechnology, Faculty of Sciences and Techniques, Sidi Mohamed Ben Abdellah University, BP 2202, Imouzzer \\ Road 30000 Fez, Morocco
}

Email: saad.ibnsouda@usmba.ac.ma

Received: 19 Jan 2017 Revised and Accepted: 19 Jun 2017

\section{ABSTRACT}

Objective: The aim of the present study was to evaluate the antifungal potential of $\beta$-Ionone; carvone and 1,8-cineole which are three essential oil components.

Methods: For that purpose, the minimum inhibitory (MIC) and fungicidal (MFC) concentrations of these compounds were determined by the microdilution method using the 96 well microtiter plates. The efficiency of these compounds was tested against the spores of Penicillium expansum; a strain responsible for huge post-harvest losses during storage of fruits and capable of producing patulin, a very dangerous mycotoxin for the human health.

Results: The obtained results showed a very strong inhibition of the growth of $P$. expansum spores with very low MIC values determined for $\beta$ Ionone (0.625 \%); Carvone (0.3125\%) and 1,8-cineol (0.078125\%). In addition, the evaluation of MFCs for the tested essential oil components showed that $\beta$-Ionone and carvone molecules exhibited the same MFCs at $5 \%$ against $P$. expansum spores. However, the best fungicidal activity was found with the 1,8-cineole molecule at a concentration of $1.25 \%$ vis-à-vis of the spores of this strain.

Conclusion: This study, which shows for the first time the antifungal potential of these three molecules against this strain, also allows to highlight the possibility of using these essential oil compounds in the formulation of commercial antifungal products.

Keywords: Antifungal activity, Penicillium expansum spores, $\beta$-Ionone, carvone, 1,8-cineole

(C) 2017 The Authors. Published by Innovare Academic Sciences Pvt Ltd. This is an open access article under the CC BY license (http://creativecommons.org/licenses/by/4.0/) DOI: http://dx.doi.org/10.22159/ijpps.2017v9i8.17169

\section{INTRODUCTION}

The Penicillium genus is one of the most known genera of fungi with Aspergillus and Paecilomyces [1]. It consists by more than 300 species [2] some of which are well known for their positive roles. Indeed, some Penicillium species such as $P$. roqueforti, $P$. nalgiovense or $P$. camemberti are used in cheese production processes in the food industry. Other species of the Penicillium genus such as $P$. chrysogenum and $P$. notatum are known for their positive contributions in the production of the penicillin antibiotic for the medical field.

However, several other members of this family are rather known for their negative roles and their implications in huge damages in various fields [3-5]. Indeed, it is the case for example of $P$. digitatum, $P$. italicum and $P$. expansum which are responsible for the blue and green moulds which are post-harvest diseases of fruits including citrus and apples [6]. These fungi are capable to colonizing different types of substrates; they can survive in extreme environmental conditions and they can produce a multitude of very dangerous mycotoxins for animal and human health and which can induce mutagenic, teratogenic and neurotoxic effects [7-10]. The $P$. expansum strain is known in the scientific literature for its capacity to produce among other mycotoxins, the patulin which is one of the most toxic for the human health [11-12].

Thus, several fungicides, such as benzimidazoles, aromatic hydrocarbons, iprodione, thiabendazole or sterol biosynthesis inhibitors, are used in the fruit storage sites to prevent decay caused by these fungi after harvesting [13-14]. Several other substances with antifungal effect were proposed to reduce the losses caused by this strain, and among these, the antifungal potential of essential oils has been regularly reported in the scientific literature.

With volatile properties, the essential oils are natural products with complex chemical compositions. They are used for centuries for their various antibacterial, antioxidant, antifungal, antiinflammatory, insecticidal properties [15-16]. Their properties are also used, more industrially in recent decades, in various fields such as cosmetics, pharmaceuticals, or in food industries. Being composed by several tens of different molecules, some of these latter are in very high proportions in the essential oils and also confer them their bioactive properties [17]

The main objective of this study was to contribute in evaluating the antifungal potential of three essential oils compounds against the growth of the spores of this destructive fungus of the harvested fruit within the storage sites. Thus, the spores of $P$. expansum were confronted with successive concentrations of $\beta$-Ionone, carvone and 1,8-cineole in order to determine the minimum inhibitory and fungicidal concentrations of these three essential oil compounds.

\section{MATERIALS AND METHODS}

Fungal strain

The studied Penicillium expansum strain was isolated from cedar wood decay (Cedrus atlantica) from an old house located in Derb Lamté in the old Medina of Fez (Morocco). Thus, this strain was identified by the molecular biology method by amplifying the region of rDNA 5.8S. For this, the universal primers ITS1 and ITS4 were used in our laboratory [18].

Penicillium expansum strain, growth conditions and harvesting spores

The Penicillium expansum strain was cultivated on the malt extract agar medium and its growth was obtained at $25^{\circ} \mathrm{C}$. After $7 \mathrm{~d}$ of incubation, their spores were then harvested by scraping the fungal culture surface in sterile Tween-80 $(0.1 \%)$. The spore suspension was concentrated by centrifugation at $10,000 \mathrm{~g}$ for $15 \mathrm{~min}$ at $4{ }^{\circ} \mathrm{C}$ until a concentration of $10^{6}$ spores $/ \mathrm{ml}$ (counted with a hemacytometer) [19]. 


\section{Chemicals}

The volatile terpene derivatives, used in this study for the evaluation of their antifungal potential, were $\beta$-ionone (99\% pure), carvone ( $99 \%$ pure) and 1, 8-cineole (99\% pure). These three volatile derivatives are part of the chemical composition of several essential oils. The antifungal potential of these three molecules was compared to that of Fluconazole (a standard antifungal substance). The used components were purchased from Sigma-Aldrich.

\section{Antifungal activity evaluation}

The antifungal activities, the minimum inhibitory concentration (MIC) and minimum fungicidal concentration (MFC), of the tested essential oil components ( $\beta$-ionone, carvone and 1, 8-cineole) against $P$. expansum spores were studied according to the microdilution method by using 96 well microtiter plates [20-23]. Briefly, the used essential oils components were diluted in a sterile solution at $1 \%$ Tween- 80 . The malt extract medium was distributed in the wells of the microplate. Then, the tested components were diluted successively from well to well and the concentration range was from 10 to $0.01 \%$. In the control wells, an equivalent volume to that of the tested components was replaced by the sterile solution at $1 \%$ Tween-80. Then, a volume of $10 \mu \mathrm{l}$ of the fungal spore suspension which was concentrated at $10^{6}$ spores $/ \mathrm{ml}$ was added to all of the microplate wells.

Thus, the MIC that is defined as the lowest concentration without visible growth of the studied strain was determined after incubation for $48 \mathrm{~h}$ at $25^{\circ} \mathrm{C}$. The determination of the MFC was conducted by depositing a $3 \mu \mathrm{l}$ volume from microtiter plates containing $100 \mu \mathrm{l}$ of broth per well for further incubation at 25 ${ }^{\circ} \mathrm{C}$ for $72 \mathrm{~h}$ on malt extract agar. The MFC was defined as the lowest concentration with no visible growth, indicating $99.5 \%$ killing of the initial inoculum. All experiments were repeated in triplicate.

\section{RESULTS}

The antifungal evaluation results of the activities of the three tested essential oil components against the growth of Penicillium expansum spores are shown in table 1 .

Table 1: Results of MIC antifungal activities for the tested essential oil components against $P$. expansum spores

\begin{tabular}{llllll}
\hline \multirow{2}{*}{ Wells } & Concentrations & \multicolumn{2}{l}{ Penicillium expansum spores } & Fluconazole mg/ml (w/v) \\
\cline { 3 - 6 } & & $\beta$-Ionone \% (v/v) & Carvone \% (v/v) & $\mathbf{1 , 8 - c i n e o l e ~ \% ~ ( v / v ) ~}$ & - \\
\hline 1 & 10 & - & - & - & - \\
2 & 5 & - & - & - & - \\
3 & 2.5 & - & - & - & - \\
4 & 1.25 & - & - & - & + \\
5 & 0.625 & + & - & - & + \\
6 & 0.3125 & + & + & - & + \\
7 & 0.15625 & + & + & + & + \\
8 & 0.078125 & + & + & + & + \\
9 & 0.0390625 & + & + & + & + \\
10 & 0.01953125 & + & + & + & + \\
11 & 0.009765625 & + & + & + & + \\
\hline
\end{tabular}

+: presence of growth; -: absence of growth; positive control: P. expansum spores suspensions in Extract Malt Broth supplemented with agar $(0.15 \%$ $\mathrm{w} / \mathrm{v}$ )

Thus, as can be seen in table 1 , the compounds used in this study had a significant antifungal effect on the growth of $P$. expansum spores. Indeed, for the $\beta$-Ionone molecule, the first concentration at which no visible growth of the spores was observed after the incubation time was $0.625 \%$. At the same time, the concentration corresponding to the MIC of the carvone molecule against $P$. expansum was $0.3125 \%$ when that of the 1,8 -cineole was only $0.078125 \%$.

Thus, among all the tested volatile terpene compounds with antifungal effect in the present work, the one that has shown the best efficacy against the growth of $P$. expansum spores was 1 , an 8cineole molecule with the lowest MIC found. It is obviously followed by carvone and $\beta$-Ionone compounds, respectively. This reflects a greater sensitivity of the $P$. expansum spores in the previously established order of the molecules used in the present work $(1,8$ cineole $>$ carvone $>\beta$-Ionone).

On the other hand, the obtained results for the determination of minimum fungicidal concentrations with these compounds almost follow the same line as that of the MICs and are reported in table 2. Indeed, we found that the corresponding concentrations to MFC for the $\beta$-Ionone and carvone compounds, for which the initial inoculum of the P. expansum spores was killed, were the same. They were $5 \%$ for these two tested molecules (table 2).

Table 2: Results of the determined MFCs for the tested molecules against $P$. expansum spores

\begin{tabular}{lllll}
\hline & \multicolumn{2}{l}{ Penicillium expansum spores } & \\
\cline { 2 - 5 } & $\boldsymbol{\beta}$-Ionone \% (v/v) & Carvone \% (v/v) & $\mathbf{1 , 8 - c i n e o l e ~ \% ~ ( v / v ) ~}$ & Fluconazole $\mathbf{~ m g} / \mathbf{m l ~}(\mathrm{w} / \mathrm{v})$ \\
\hline MFC & 5 & 5 & 1.25 & $\mathrm{nd}$ \\
\hline
\end{tabular}

nd: not determined

However, as with its MIC against the spores of the studied strain, the molecule of 1,8-cineole showed the lowest MFC obtained compared to the two other molecules.

The volume of $3 \mu \mathrm{l}$, which showed no visible growth on malt extract agar during the determination of the MFC, was from to the wells of the microplate whose concentration was $1.25 \%$ of the 1, 8-cineole compound (table 2). These obtained results confirmed the very high sensitivity of the spores of this $P$. expansum strain to the molecule of 1 , 8-cineole.
Compared to the antifungal potential of the tested essential oils compounds, a test was performed with fluconazole which is a recognised antifungal substance and used in the medical field.

The antifungal evaluation results of the MIC activities of fluconazole against the growth of Penicillium expansum spores are also shown in table 1.

Thus, the obtained results with the fluconazole (table 1) showed that the MIC of this molecule against the growth of this fungal strain 
corresponded to $0.625 \mathrm{mg} / \mathrm{ml}$. As regards to the MFC, it has not been determined even at a concentration of $10 \mathrm{mg} / \mathrm{ml}$ of fluconazole (table 2).

\section{DISCUSSION}

The involvement of the Penicillium expansum strain in the postharvest damage in the agricultural sector has already been reported in several studies. In fact, this strain is responsible for huge losses after harvesting the fruit and in particular that of apples [24-27]. The results obtained after the antifungal tests performed on spores of this strain have shown the high efficiency of the three used compounds. This is reflected by the low values of the concentrations of these essential oil compounds which were sufficient to inhibit the growth of these spores.

Several authors have reported regularly in recent decades the important antibacterial and antifungal potential of the essential oils as a whole.

Indeed, Zhao et al. [28] recently reported in their works on the antifungal activity of the Inula britannica essential oil that the inhibition rate of the latter at $1 \mathrm{mg} / \mathrm{ml}$ against spore germination of Phytophthora capsici and Fusarium oxysporum were 98.26 and 96.54 $\%$, respectively. They also indicated that their essential oil showed a significant degree of control against the Colletotrichum orbiculare (87.89 \%), Pyricularia grisea (87.35 \%), and Fusarium oxysporum $f$. sp. vasinfectum (73.32\%) strains.

Similar results were also reported by Tzortzakis et al. [29] which indicated that the use of the lemongrass essential oil (Cympopogon citratus L.) at $25 \mathrm{ppm}$ was significantly inhibited the spore production in several tested fungal species: $70 \%$ for Botrytis cinerea, $58 \%$ for Colletotrichum coccodes, $41 \%$ for Aspergillus niger, $40 \%$ for Cladosporium herbarum and $35 \%$ for Rhizopus stolonifer.

More recently, da Rocha et al. [30] showed that salicylic acid has the potential to completely inhibit the germination of spores of Penicillium expansum at a concentration of $2.5 \mathrm{mmol}$.

On the other hand, the bio-activity and the efficiency of essential oils are due to the tens of terpene and aromatic compounds which constitute them. It is the case for example of thymol, carvacrol, pcymene, and $\gamma$-terpinene which are components of the Oregon essential oil [17]. The authors of the study [17] have shown that each of these four terpenes inhibited the growth of the two tested bacterial strains. Carvacrol and p-cymene showed the same MIC against Staphylococcus aureus $(1.25 \mathrm{mg} / \mathrm{ml})$ and Escherichia coli $(2.5$ $\mathrm{mg} / \mathrm{ml}$ ). The MICs of thymol were $0.31 \mathrm{mg} / \mathrm{ml}$ against $S$. aureus and $5 \mathrm{mg} / \mathrm{ml}$ against E. coli when those of $\gamma$-terpinene were 2.5 and 5 $\mathrm{mg} / \mathrm{ml}$ for both strains, respectively.

In addition, Matan et al. [31] reported that the use of clove oil at a concentration of $10 \mu \mathrm{l} / \mathrm{ml}$ or its major component (eugenol) at a concentration of $5 \mu \mathrm{l} / \mathrm{ml}$ with an atmospheric RF plasma treatment at $40 \mathrm{~W}$ was able to prevent the growth of Escherichia coli, Salmonella typhimurium and Staphylococcus aureus on the chicken eggs.

Although the compounds used in this study have not been the subject of many investigations in terms of antifungal activities, we have recently highlighted the anti-adhesive potential of these compounds against the Penicillium expansum spores on the cedar wood surface which is widely used in the constructions of historical monuments of the medina of Fez. Indeed, the treated surface of cedar wood by the $\beta$-Ionone showed an inhibition rate of spore adhesion of $61.15 \%$ when that of the treated sample with the 1, 8cineole compound was $83.39 \%$ compared to the spore adhesion rate on the untreated cedar samples [32].

On the other hand, if the antimicrobial potential of essential oils is well established in the scientific literature, it remains a major problem concerning the concentration and chemical composition of the molecules which constitute the essential oils of various plants. Indeed the latter are influenced by several factors such as climatic, geographical location, environmental, etc; thus, their antimicrobial potential may also be affected according to their extraction periods.

Therefore, it might be more interesting to evaluate the antibacterial and antifungal potential of these terpene compounds. Some of these molecules are present in very high proportions and constitute the major components of essential oils. It is also in this objective that the present work was realized. Unlike essential oils, the advantage, of the use of these compounds, would be to have molecules whose the biological properties as well as the chemical composition would not be influenced by the different factors mentioned above.

However, as with essential oils, the mechanism of action by which these molecules attack microorganisms is still very poorly explained in the scientific literature. Some authors have even suggested that this multitude of varied chemical molecules would not appear to have specific targets [33-34]. In fact, their lipophilic properties allow them to destabilize the structures of the macromolecules (polysaccharides, fatty acids and phospholipids, etc) through the cell wall and the cytoplasmic membrane of microorganisms [35-37]. Thus, the destabilized membranes of the attacked microorganisms become permeable. What causes a loss of ions and thus induces a difference of potential at the membranaire level [38-41]. Always in the same vein, the lipids and proteins would be also affected [39; 42].

However, the mechanism of action of some major essential oil components is better known in the literature. Indeed, this is the case for example for thymol and carvacrol which are two major compounds of the Thyme and Oregon essential oils. Thus, Xu et al. [43] reported in their work on the mechanism of action of these two molecules against Escherichia coli that they have the ability to permeabilize and depolarize the cytoplasmic membrane of this bacterial strain.

\section{CONCLUSION}

The obtained results in the present study demonstrated that these three compounds ( $\beta$-Ionone; carvone and 1,8-cineole) have a real antifungal potential and they could be used as antifungal agents as well as to significantly reduce (or completely eliminate) the growth of Penicillium expansum during the storage of apples. They could also be used as antifungal agents against the growth of other important pathogenic fungal which present major risks both in the food industry and in the medical field. However, additional research is needed to better understand their mechanisms of action against the fungi in order to lead to the formulation of commercial antifungal products.

\section{AUTHORS CONTRIBUTION}

Hassan Barkai carried out the work presented in this manuscript; Ibnsouda Koraichi Saad wrote the manuscript, And Elabed Soumya and Guissi Sanae contributed in its correction.

\section{CONFLICT OF INTERESTS}

The authors declare that they have no conflict of interest.

\section{REFERENCES}

1. Houbraken J, Samson RA. Phylogeny of Penicillium and the segregation of Trichocomaceae into three families. Stud Mycol 2011;70:1-51

2. Pitt JI. A Laboratory guide to common Penicillium species. Common Sci Ind Res Org Div Food Processing, North Ryde, NS. W. Australia, Academic Press: Inc. Ltd. London; 1991.

3. He S, Ren X, Lu Y, Zhang Y, Wang Y, Sun L. Microemulsification of clove essential oil improves its in vitro and in vivo control of Penicillium digitatum. Food Control 2016;65:106-11.

4. Zeng R, Zhang A, Chen J, Fu Y. Postharvest quality and physiological responses of clove bud extract dip on 'Newhall' navel orange. Scientia Horticulturae 2012;138:253-8.

5. Kellerman M, Erasmus A, Cronje PJR, Fourie PH. Thiabendazole residue loading in the dip, drench and wax coating applications to control green mould and chilling injury on citrus fruit. Postharvest Biol Technol 2014;96:78-87.

6. Droby S, Eick A, Macarisin D, Cohen L, Rafael G, Stange R, et al. Role of citrus volatiles in host recognition, germination and growth of Penicillium digitatum and Penicillium italicum. Postharvest Biol Technol 2008;49:386-96.

7. Frisvad CJ, Skouboe P, Samson AR. Taxonomic comparison of three different groups of aflatoxin producers and new efficient 
producer of aflatoxin B1, sterigmatocystine and 3Omethylsterigmatocystine Aspergillus rumbelli sp. nov. Syst Appl Microbiol 2005;28:442-53.

8. Prakash B, Shukla R, Singh P, Kumar A, Mishra PK, Dubey NK. Efficacy of chemically characterized Piper betle L. essential oil against fungal and aflatoxin contamination of some edible commodities and its antioxidant activity. Int J Food Microbiol 2010;142:114-9.

9. Prakash B, Shukla R, Singh P, Mishra PK, Dubey NK, Kharwar RN. Efficacy of chemically characterized Ocimum gratissimum $L$ essential oil as an antioxidant and a safe plant based antimicrobial against fungal and aflatoxin B1 contamination of spices. Food Res Int 2011;44:385-90.

10. Ravindra S, Priyanka S, Bhanu P, Dubey NK. Antifungal, aflatoxin inhibition and antioxidant activity of Callistemon lanceolatus (Sm.) sweet essential oil and its major component 1,8-cineole against fungal isolates from chickpea seeds. Food Control 2012;25:27-33.

11. da Rocha NAC, Luiz C, Maraschin M, di Piero RM. Efficacy of salicylic acid to reduce Penicillium expansum inoculum and preserve apple fruits. Int J Food Microbiol 2016;221:54-60.

12. Wright SAI, de Felice DV, Ianiri G, Pinedo-Rivilla C, de Curtis F, Castoria R. Two rapid assays for screening of patulin biodegradation. Int J Environ Sci Technol 2014;11:1387-98.

13. Yahyazadeh M, Omidbaigi R, Zare R, Taheri H. Effect of some essential oils on mycelial growth of Penicillium digitatum Sacc. World J Microbiol Biotechnol 2008;24:1445-50.

14. Fan Q, Tian SP. Postharvest biological control of Rhizopus rot of nectarine fruits by Pichia membranefaciens. Plant Dis 2000; 84:1212-6.

15. Kordali S, Kotan R, Mavi A, Cakir A, Ala A, Yildirim A. Determination of the chemical composition and antioxidant activity of the essential oil of Artemisia dracunculus and of the antifungal and antibacterial activities of Turkish Artemisia absinthium, A-dracunculus, Artemisia santonicum, and Artemisia spicigera essential oils. J Agric Food Chem 2005;53:9452-8.

16. Pezo D, Salafranca J, Nerin C. Design of a method for generation of gas phase hydroxyl radicals, and use of HPLC with fluorescence detection to assess the antioxidant capacity of natural essential oils. Anal Bioanal Chem 2006;385:1241-6.

17. Mariateresa C, D'Arrigo M, Giuseppina M, Francesco C, Maria GS, Dorotea $\mathrm{M}$, et al. Interaction of four monoterpenes contained in essential oils with model membranes: implications for their antibacterial activity. J Agric Food Chem 2007;55:6300-8.

18. Zyani $M$, Mortabit D, Mostakim M, Iraqui $M$, Haggoud $A$, Ettayebi $\mathrm{M}$, et al. Cellulolytic potential of fungi in wood degradation from an old house at the Medina of Fez. Ann Microbiol 2009;59:699-704.

19. Barkai H, Elabed S, Sadiki M, Balouiri M, Ibnsouda KS. Antifungal activity and physicochemical surface properties of the momentaneously exposed Penicillium expansum spores to carvacrol. Res J Microbiol 2016;11:178-85.

20. Tian J, Chen YX, Ma BX, He JS, Tong J, Wang YW. Drosera peltata Smith var. lunata (Buch.-Ham.) C. B. Clarke as a feasible source of plumbagin: phytochemical analysis and antifungal activity assay. World J Microbiol Biotechnol 2014;30:737-45.

21. Tatjana S, Tanja B, Katarina S, Marina S, Dejan G, Ivica D, et al. Antifungal activity of selected essential oils against fungi isolated from the medicinal plant. Ind Crops Prod 2014;55:116-22.

22. Savita K, Neetu P, Mehak D, Anil KC. Antibacterial, antioxidant, chemical constituents, and cytotoxicity evaluation of terminalia arjuna (roxb. ex dc.) weight and arn. Asian J Pharm Clin Res 2017;10:412-7.

23. Elin YS, Irda F, Eriwan S, Dewi S. The study of antifungal activity from indigenous plants from indonesia: an in vitro study. Asian J Pharm Clin Res 2017;10:196-201.

24. Jie W, Hong-Yan W, Xiao-Ming X, Peng-Peng L, Kai-Yun W. Synergistic effect of Lentinula edodes and Pichia membranefaciens on inhibition of Penicillium expansum infections. Postharvest Biol Technol 2013;81:7-12.

25. Martins ML, Gimeno A, Martins HM, Bernardo F. Co-occurrence of patulin and citrinin in portuguese apples with rotten spots. Food Addit Contam 2002;19:568-74.
26. $\mathrm{Xu} \mathrm{XM}$, Berrie AM. Epidemiology of mycotoxigenic fungi associated with Fusarium ear blight and apple blue mould: a review. Food Addit Contam 2005;22:290-301.

27. Nicoleta AM, Ana YRV, Anca IN, Olga MB, Robert SF. Influence of processing parameters on the pulsed-light inactivation of Penicillium expansum in apple juice. Food Control 2014;41:27-31.

28. Zhao T, Gao F, Zhou L, Song TY. Essential oil from Inula britannica extraction with $\mathrm{SF}-\mathrm{CO}_{2}$ and Its antifungal activity. J Integr Agric 2013;12:1791-8.

29. Tzortzakis NG, Costas ED. Antifungal activity of lemongrass (Cympopogon citratus L.) essential oil against key postharvest pathogens. Innovative Food Sci Emerging Technol 2007; 8:253-8.

30. da Rocha ACN, Maraschin M, Di Piero RM. Antifungal activity of salicylic acid against Penicillium expansum and its possible mechanisms of action. Int J Food Microbiol 2015;215:64-70.

31. Narumol M, Mudtorlep N, Nirundorn M. Antibacterial activity of essential oils and their main components enhanced by atmospheric RF plasma. Food Control 2014;39:97-9.

32. Barkai H, Elabed S, Sadiki M, Balouiri M, Maataoui H, Ibnsouda SK. Evaluation of hydrophobic-hydrophilic properties and antiadhesive potential of the treated cedar wood by two essential oil components against bioadhesion of Penicillium expansum spores. J Appl Sci 2016;16:372-9.

33. Carson CF, Mee BJ, Riley TV. Mechanism of action of Melaleuca alternifoliate (tea tree) oil on Staphylococcus aureus determined by time-kill, lysis, leakage and salt tolerance assays and electron microscopy. Antimicrob Agents Chemother 2002;46:1914-20.

34. Bakkali F, Averbeck S, Averbeck D, Idaomar M. Biological effects of essential oils-a review. Food Chem Toxicol 2008;46:446-75.

35. Cox SD, Mann CM, Markham JL, Bell HC, Gustafson JE, Warmington JR, et al. The mode of antimicrobial action of essential oil of Melaleuca alternifolia (tea tree oil). J Appl Microbiol 2000;88:170-5.

36. Lambert RJW, Skandamis PN, Coote P, Nychas GJE. A study of the minimum inhibitory concentration and mode of action of oregano essential oil, thymol and carvacrol. J Appl Microbiol 2001;91:453-62.

37. Oussalah M, Caillet S, Lacroix M. Mechanism of action of Spanish oregano, Chinese cinnamon, and savory essential oils against cell membranes and walls of Escherichia coli 0157:H7 and Listeria monocytogenes. J Food Prot 2006;69:1046-55.

38. Ultee A, Kets EP, Alberda M, Hoekstra FA, Smid EJ. Adaptation of the food-borne pathogen Bacillus cereus to carvacrol. Arch Microbiol 2000;174:233-8.

39. Ultee A, Bennik MH, Moezelaar R. The phenolic hydroxyl group of carvacrol is essential for action against the food-borne pathogen Bacillus cereus. Appl Environ Microbiol 2002;68:1561-8

40. Di Pasqua R, Hoskins N, Betts G, Mauriello G. Changes in membrane fatty acids composition of microbial cells induced by addition of thymol, carvacrol, limonene, cinnamaldehyde, and eugenol in the growing media. J Agric Food Chem 2006:54:2745-9.

41. Turina AV, Nolan MV, Zygadlo JA, Perillo MA. Natural terpenes: self-assembly and membrane partitioning. Biophys Chem 2006;122:101-13.

42. Burt S. Essential oils: their antibacterial properties and potential applications in foods-a review. Int J Food Microbiol 2004;94:223-53.

43. Xu J, Zhou F, Ji BP, Pei RS, Xu N. The antibacterial mechanism of carvacrol and thymol against Escherichia coli. Lett Appl Microbiol 2008;47:174-9.

\section{How to cite this article}

- $\quad$ Barkai Hassan, Elabed Soumya, Guissi Sanae, Ibnsouda Koraichi Saad. Evaluation of the antifungal activities of three essential oil components against Penicillium expansum spores. Int J Pharm Pharm Sci 2017;9(8):56-59. 